\title{
Use of a Therapeutic Communication Simulation Model in Pre-Licensure Psychiatric Mental Health Nursing: Enhancing Strengths and Transforming Challenges
}

\author{
Marjorie Hammer*, Sylvia Fox, Michelle DeCoux Hampton \\ School of Nursing, Samuel Merritt University, 3100 Summit Street, $3^{\text {rd }}$ Floor, Oakland \\ *Corresponding Author: mhammer@samuelmerritt.edu
}

Copyright (C) 2014 Horizon Research Publishing All rights reserved.

\begin{abstract}
Nurse educators are challenged to prepare students to graduate with a high level of communication skill to effectively work with patients, families and professional colleagues. This manuscript describes an innovative pedagogical model developed for teaching therapeutic communication skills to pre-licensure nursing students through the use of simulation. This novel, theoretically based teaching and learning strategy is a replicable model that includes student and faculty preparation; pre- and post-assignments; tools for active engagement of students as role players or observers who utilize therapeutic communication techniques and critical thinking about therapeutic communication theory; tools for self and peer evaluation; and opportunities for inter-professional communication skill development. The model also serves as an alternative milieu to the clinical site. A brief literature review provides a theoretical and socio-economic framework.
\end{abstract}

Keywords Psychiatric Mental Health Nursing, Therapeutic Communication, Simulation, Role Play, Clinical Skill Development

\section{Introduction}

Creative teaching and experiential learning have emerged from the explosion in technological innovation; however, literature describing the use of simulation in psychiatric mental health nursing (PMHN) is scant. This paper provides a literature review of simulation in PHMN; describes a novel, replicable, low-fidelity PMHN therapeutic communication simulation model designed by nursing faculty at an urban health science university; and discusses lessons learned and future recommendations. This PMHN simulation model calls for experiential, real time exploration and demonstration of knowledge of psychiatric diagnoses and treatments, and the responses and responsibilities of the professional nurse in observation, assessment, communication, decision making, therapeutic intervention, and triage. Reflection and articulation of critical thinking and judgment among peers during debriefing contributes to skill development and attitude shifts. Core competencies can be evaluated and reinforced.

\section{Review of Literature}

Developments in pedagogy and technology are transforming teaching of the complex critical skill set essential to today's nurse. Role play and video capture of the therapeutic alliance are tools that have been utilized routinely in graduate programs in the psychiatric field since the availability of this technology; however, these modalities are little explored in the teaching of pre-licensure psychiatric mental health nursing (PMHN) and therapeutic communication skills. Simulation is an accessible, low cost pedagogy where knowledge and skill acquisition is possible through active student observation and engagement, repeated practice, immediate peer and faculty feedback, and dialogue and teamwork (Barnett, Everly, Parker, \& Links, 2005). Rigorous attention to simulation design and management is essential for successful learning outcomes, including the development of the use of self as a clinical tool. It is recommended that students be provided with clearly written knowledge and behavioral objectives for each simulation as a framework for applying theory to dynamic patient situations (Jeffries, 2007). For the clinician, assessment of the context of the current health problem, including culture, language, education, spirituality, economics, and other patient and family concerns is critical (Jeffries, 2007). Priorities for care are determined in light of this knowledge and context.

Healthcare literature provides examples demonstrating integration of didactic and clinical teaching through use of simulation. One model, pioneered in the 1970's, is the Objective Structured Clinical Examination (OSCE), a 
20-minute simulated encounter with a short debriefing. The OSCE provides close encounters for the evaluation of knowledge base and cognitive, communication, psychosocial and technical skills (Linder \& Pulsipher, 2008; Kardong-Edgren, Starkweather, \& Ward, 2008; Rauen, 2004; Robertson, 2006; Rhodes \& Curran, 2005). Students demonstrate the ability to apply course concepts to practice, think critically, intervene effectively, communicate therapeutically and work as a team in a variety of settings. Students report that the OSCE model increases their knowledge, prepares them for clinical, and increases clinical confidence. Simulation provides an opportunity to learn and practice in a safe environment, and has been associated with improvement in skills of communication and critical judgment (Bambini, Washington, \& Perkins, 2009). Students may be required to complete a communication course prior to admission to nursing school; bridging the gap between theory and practice remains an issue (Kluge \& Glick, 2006). Medical students in a randomized controlled study of using peer role play (RP) versus standardized patient (SP) simulation to teach communication skills reported both were highly acceptable and highly realistic; peer RP is less expensive (Bosse et al., 2010).

The mind and heart of the simulation process is debriefing, which engages the skills of self-reflection and discovery (Kardong-Edgren et al., 2008). Harvard's Debriefing Assessment for Simulation in Healthcare (DASH) is a tool helpful for assessing debriefing for diverse disciplines and courses, educational objectives, and physical and time frameworks (Simon, Raemer \& Rudolph, 2009). The DASH model, based on thirty-five years of research to improve professional effectiveness through reflective practice, recommends debriefing that promotes "a conversation... in which participants explore, analyze and synthesize their actions and thought processes, emotional states and other information to improve performance in real situations..." (Simon et al., 2009). Debriefing provides an opportunity for students to think critically, discuss rationales for behavior, discover what was done well and what could have been done differently, and integrate lessons learned into their practice. Critical skills for the nursing professional include the ability to provide appropriate feedback and "rigorous reflection", rather than withholding thoughts and feelings to avoid confrontation, hurt or defensiveness which can "perpetuate medical mistakes and undermine patient safety...[in] the real clinical environment" (Rudolph, Simon, Dufresne, \& Raemer, 2006, p.50). The DASH model provides a framework of safety and rigor for student development of these essential critical reasoning processes and ethical behaviors (Simon et al., 2009). A central feature of DASH is the concept of "debriefing with good judgment": disclosure of faculty judgments and trainee assumptions and rationales for actions are pivotal to learning and growth (Rudolph et al., 2006). Through the deconstruction of internal frames, trainees engage in "... rigorous self-reflection... to reframe internal assumptions and feelings, ...recognize and resolve pressing clinical and behavioral dilemmas raised by the simulation, ... and take action to achieve better results in the future" (Rudolph et al., p. 49). A stance of advocacy and inquiry sheds light on the judgment of the instructor and the trainee, thus supporting critical, evaluative judgments in the context of a trusting relationship.

While Nehring and Lashley's (2004) comprehensive international study found that simulation is rarely used in psychiatric mental health nursing (PMHN) courses, reports are emerging, including the use of SPs, static manikins, RPs, high-fidelity manikins, and e-learning to increase therapeutic communication skills. When Robinson-Smith, Bradley, and Meakim (2009) utilized a convenience sample of nursing students to evaluate the use of SPs in scenarios to teach assessment skills, including the mental status examination and a suicide risk assessment, students perceived that their confidence, learning, and critical thinking improved. Davis, Josephsen, and Macy (2012) utilized SPs for PMHN simulation when clinical sites were lacking. Challenges included the ability to recruit an adequate number of SPs and to give helpful feedback. Hermanns, Lilly, and Crawley (2011) used a model of a faculty-led simulation with a static manikin to simulate an attempted suicide. The goal was to immerse students in a realistic psychiatric-mental health event in a safe, structured environment. Faculty was present throughout to provide guidance, questions, prompts, and cautions. Students supported the use of simulation in PMHN as a teaching/learning strategy: "Now I know what to do" and awareness of challenges (Hermanns et al., p. e44). Sleeper and Thompson (2008) designed and implemented a simulation for PMHN students to increase their confidence and communication skills prior to the PMHN clinical experience. They utilized a high fidelity mannequin with pre-programmed responses. Evaluation of student performance revealed that simulation augmented theory and enhanced transferability of knowledge to practice. Guise, Chambers, and Valimaki (2008) utilized e-learning with virtual patients to develop fundamental PMHN skills. Kidd, Morgan, and Savery (2012) had students participate in Second Life to design and create nurse-patient relationships in order to practice client assessment, communication and safety. Kameg, Howard, Clochesy, Mitchell, and Suresky (2010) also used high fidelity human simulation with a goal of improving student self-efficacy in utilization of communication skills with mental health patients. The authors reported statistically significant improvement in student sense of self-efficacy and self-efficacy in communication following the simulation experience.

One issue raised by critics of simulation learning is that existing research does not confirm its efficacy as an educational tool, but merely provides anecdotal feedback and/or perceptions from students and faculty (Brown, 2008; Comer, 2005). Thus, internal and external validity may be absent. Nehring and Lashley's (2004) comprehensive study of the use of simulation in nursing education internationally concurred that more rigorous study is needed to assess efficacy.

Simulation in undergraduate pre-licensure nursing 
education has demonstrated ability to increase retention and critical thinking (Jeffries, Woolf, \& Linde, 2003), provide opportunities to think and act like nurses in safe non-threatening environments, and increase student satisfaction (McCausland, Curran, \& Cataldi, 2004). While a few programs that utilize simulation to teach communication skills and critical thinking in PMHN or medical schools have been described, more description and study of replicable, efficacious models for psychiatric-mental health communication instruction are needed.

\section{Model}

This university's PMHN faculty and simulation experts allied to create replicable, day-long, small group, low-fidelity simulation experiences for students during the PMHN pre-licensure course. Role plays serve as a template for exploration of competency related to assessment, signs and symptoms of psychiatric diagnoses, evidence-based treatment recommendations, therapeutic communication skills (including the "therapeutic use of self") and interdisciplinary communication and practice.

Each student in the pre-licensure PMHN course participates in two simulation days that are equivalent to two on-site clinical days. The focus of the first day is on becoming familiar with the use of simulation as a learning tool, fundamentals of communication within the psychiatric nursing milieu, and self-reflection and debriefing skill development. The second day builds on the first, focusing on deepening understanding of communication principles, therapeutic communication techniques, and skilled professional relationships. Students from each of six clinical groups are assigned in dyads or triads to attend simulation. Students are not provided with scenarios or roles prior to simulation as this may contribute to anticipatory anxiety and was not deemed necessary for learning to occur. Diagnoses that may be a part of the role play are provided so that students can review the nursing role in relation to these health concerns. As is the norm for a clinical day, attendance is mandatory and students are evaluated as satisfactory or unsatisfactory. Each simulation day has associated "pre-" and "post" assignments [Figure 1: Sample Pre- and Post- Assignments].

At the beginning of each simulation day, students are provided with an overview of the day, including goals and objectives, and the process and expectations of students and faculty [Figure 2: Sample Objectives].

Faculty describes and supports self-reflection and active engagement, particularly as an aspect of the debriefing. A pre-videoed scenario of faculty demonstrating a patient-nurse interaction is viewed and discussed, utilizing the therapeutic communication evaluation tool as a model for the communication simulation and debriefing [Figure 3: Therapeutic Communication Evaluation Tool].

Students are assured in pre-briefing that the communication simulation is a teaching-learning experience that will not be graded; the intention is to provide an opportunity to practice therapeutic communication in a safe setting. Students are introduced to the conceptual framework provided by the DASH model: they are encouraged to engage in the simulations with curiosity, openness, and a non-judgmental attitude. Students complete the free validated, reliable PNCI Simulation Effectiveness Tool (SET, 2012) at the end of each simulation day.

\begin{tabular}{|c|c|}
\hline $\begin{array}{c}\text { Pre-assignment: } \\
\text { Self-Reflection }\end{array}$ & Bring a hard copy of your pre-assignment to your simulation day (1-2 pages) \\
\hline Day One & Reflect on your expectations and concerns regarding simulation. \\
\hline Day Two & $\begin{array}{c}\text { Reflect on your initial simulation experience. Describe one "ah-hah" moment (something you didn't know or } \\
\text { hadn't thought about that made an impression on you). What were your personal thoughts? How can you } \\
\text { generalize your experience to other clinical situations you may experience as a nursing professional? }\end{array}$ \\
\hline Post-assignment & Email your post assignment to your PMHN simulation faculty within 24 hours of the simulation. \\
\hline Day One & Complete a brief Mental Status Examination (MSE) on one of the simulated patients. \\
\hline Day Two & Complete an SBAR on the simulated patient experience in which you participated. \\
\hline
\end{tabular}

Figure 1. Sample Pre- and Post- Assignments

The student will demonstrate the ability to:

\begin{tabular}{|rl|}
\hline 1. & Initiate and engage in communication with a simulated hospitalized patient with mental health concerns. \\
\hline 2. & Reflect on one's own behavior and discuss this with openness and an attitude of curiosity. \\
\hline 3. & $\begin{array}{l}\text { Participate in debriefing by sharing one's own thoughts, perceptions, reactions, and recommendations with an attitude of kindness and } \\
\text { respect. }\end{array}$ \\
\hline 4. & $\begin{array}{l}\text { Effectively utilize communication principles in facilitating professional relationships with clients, families and health care system } \\
\text { colleagues. }\end{array}$ \\
\hline 5. & Complete an accurate and effective SBAR. \\
\hline 6. & $\begin{array}{l}\text { Think and act critically re: mental health services and the role of the nurse, including basic understanding of psychiatric diagnosing and } \\
\text { treatment, utilization of the mental status examination; and the provision of safe patient-centered care that is compassionate, caring, and } \\
\text { culturally sensitive within the legal and ethical mandates of the health profession. }\end{array}$ \\
\hline
\end{tabular}




\begin{tabular}{|c|c|c|c|}
\hline Effective Communication & Non-effective Communication & & \\
\hline Non-verbal & & Time: & Notes: \\
\hline$\square$ Facing client & $\square$ Turned away from patient & & \\
\hline$\square$ Relaxed posture & $\square$ Tense or intimidating posture & & \\
\hline$\square$ Hands, arms open & $\square$ Hands folded or arms crossed & & \\
\hline$\square$ Private location & $\square$ Other clients or staff in hearing distance & & \\
\hline$\square$ Conveys warmth and caring & $\square$ Appears apathetic, disinterested, fearful or anxious & & \\
\hline Verbal & & Time: & Notes: \\
\hline $\begin{array}{l}\square \text { Soothing, non-threatening tone } \\
\text { of voice }\end{array}$ & $\square$ Intimidating or passive tone, sounding rushed & & \\
\hline $\begin{array}{l}\square \text { Confidentiality assured within } \\
\text { treatment environment (excluding } \\
\text { any revelation of danger to self or } \\
\text { others) }\end{array}$ & $\begin{array}{c}\square \text { No discussion of confidentiality or promises to keep secrets no matter } \\
\text { what }\end{array}$ & & \\
\hline $\begin{array}{l}\square \text { Attentive to client comfort (i.e. } \\
\text { hunger, thirst, cold or heat, fatigue) }\end{array}$ & $\square$ Pushing interview despite obvious signs of discomfort or intolerance & & \\
\hline $\begin{array}{l}\square \text { Focus remained primarily on } \\
\text { client, mostly patient disclosure }\end{array}$ & $\square$ Interviewer talked a lot about him or herself & & \\
\hline $\begin{array}{c}\square \text { Appropriate use of open ended } \\
\text { questions }\end{array}$ & $\square$ Mostly closed-ended questions that required only one word responses & & \\
\hline $\begin{array}{l}\square \text { Able to listen to client without } \\
\text { interjecting personal bias or views }\end{array}$ & $\begin{array}{l}\square \text { Made statements indicating bias or particular opinions regarding race, } \\
\text { religion, sex, sexual orientation, culture, political or other beliefs or } \\
\text { affiliations }\end{array}$ & & \\
\hline $\begin{array}{l}\square \text { Eliciting client ideas for } \\
\text { resolution of problems }\end{array}$ & $\square$ Giving advice, imposing own agenda & & \\
\hline Active Listening & & Time: & Notes: \\
\hline$\square$ Clarifying & $\square$ Did not seem to understand what client expressed & & \\
\hline$\square$ Imparting information & $\square$ Missed opportunities for teaching & & \\
\hline $\begin{array}{l}\square \text { Self-disclosure (establishing } \\
\text { rapport and trust) }\end{array}$ & $\square$ Complete lack of or too much self-disclosure & & \\
\hline$\square$ Silence & $\square$ Chatter & & \\
\hline$\square$ Focusing & $\square$ Missed non-verbal cues given by client & & \\
\hline
\end{tabular}

Figure 3. Therapeutic Communication Evaluation Tool The client is a 25year old female admitted to an inpatient psychiatric unit after threatening suicide. The client tells the nurse s/he wants to reveal
something but it can't be shared with anyone else. The client asks the nurse to promise not to tell anyone.

Figure 4. Sample Case

All scenarios are based on material already introduced to students in the theory section of the course through lectures, readings, and assignments. Each unscripted videoed scenario is approximately five to ten minutes duration. Each student has the opportunity to be in the role of patient, nurse and observer; assignment to these three roles is random. Prior to actively engaging in the role of either patient or nurse, the student is coached by faculty and/or teaching assistants. They receive a brief report about the patient, and have an opportunity to discuss these and ask questions [Figure 4: Sample Case].

The "patient" may utilize moulage to make the scenario more realistic. Students who are not in an active role observe a live feed of the simulation from an adjacent conference room. While observing, these students complete a Mental Status Exam (MSE) to assess the "patient" and the tool for identifying whether techniques utilized are therapeutic or non-therapeutic [Figure 3]. During the role play, faculty can bookmark moments within the video that provide powerful examples of therapeutic or non-therapeutic communication, or other pivotal teaching moments, such as critical incidents, and/or assessment, treatment or ethical dilemmas. The faculty end the scenario either when the scenario reaches a natural conclusion or if the students in the role play are struggling to a point where the scenario is no longer productive.

The "nurse", "patient", and mental health faculty then join the student observers for discussion and debriefing. Harvard's Debriefing Assessment for Simulation in Healthcare (DASH) model is utilized as a number of this university's school of nursing faculty have been trained in the model and experienced its strengths (Simon, Raener \& 
Rudolph, 2009). The simulation format provides ample opportunities for formative assessment. Students serve as resources for their peers in multiple ways. Self- and peer-assessment of thoughts, feelings, and behaviors with a focus on learning is ongoing through descriptive feedback guided by the tools provided, as well as explication of the $D A S H$ guidelines for debriefing. During debriefing, segments of the video are reviewed to clarify issues, raise questions, or emphasize important concepts and skills raised by the students or faculty. The immediate availability of video enhances the group's ability to give active feedback, and recall and review any portion of the simulation second-by-second, thus refreshing and deepening the analysis, feedback and learning. These videos are logged and stored by the university's simulation center staff so that they are available for future reference and utilization. This contributes to the witnessing and evaluating of growth and development of individual student skill as well as pedagogical efficacy.

The PMHN simulation model is evolving. Initially, students participated in simulation after completing six weeks of PMHN theory and multiple days in clinical. A student was randomly selected to mentor or coach the student "nurse" providing real-time feedback to the "nurse" via microphone and earpiece; this was eliminated as students found it distracting. In the first year, students had only one opportunity to be engaged in an active role as either patient or nurse. The scenarios revolved around psychiatric diagnoses, such as anxiety, mood disorder, or schizophrenia. Students requested earlier and more frequent simulation. Now simulation begins on the first clinical day. Beginning scenarios now focus on communication skills and on challenging cases that call for assertiveness and critical thinking, such as provocative patient behaviors like gift giving, requests for or offering of personal information, requests to keep secrets, or initiations of friendship. Later in the semester, students now engage in an interdisciplinary simulation. Complex interdisciplinary scenarios were developed in collaboration with physician assistant (PA) and doctorate of podiatric medicine (DPM) faculty. The PMHN students conduct an initial assessment, demonstrate therapeutic communication with both the patient and family, call the practitioner, and utilize SBAR as a communication tool. DPM or PA students conduct an in-depth assessment, plan and order treatment, and collaborate with nursing students. Initially, evaluation of the simulation occurred informally as part of the debriefing within the simulation process. Now, in addition to debriefing, students complete the revised PNCI Simulation Effectiveness Tool (SET, 2012), a 13 -item scale.

\section{Discussion}

The psychiatric mental health nursing (PMHN) therapeutic communication simulation developed by PMHN faculty is an example of the value of simulation as a pedagogical tool for student learning, faculty monitoring, and evaluation of student knowledge and practice. It is a creative, strengths- and evidenced-based response to external and internal market demands by faculty and simulation experts that is flexible and evolving. This PMHN therapeutic communication simulation experience provides an opportunity for students to improve their professional expertise through reflective practice. With advance preparation related to clinical diagnoses, evidence-based treatment recommendations, and therapeutic communication techniques; participation or observation in each case scenario; and the active engagement of each student in each of the simulated roles (patient, family member, provider) and as observers, students engaged in "rigorous self-reflection...that helps trainees recognize and resolve pressing clinical and behavioral dilemmas...." (Rudolph et al., 2006, p.49). Students' assumptions and knowledge influence their behaviors, observations, feedback and the very outcome of the scenarios. Students can deconstruct their own and their peers' thoughts, feelings and behaviors. This active learning process engages, challenges and grows physical, emotional and intellectual knowledge and intelligence, including the student's own frame of reference.

The briefly outlined scenarios provide an opportunity for students to creatively explore and develop understanding of the emotional, intellectual and behavioral realities of clients with a variety of psychiatric diagnoses. Regardless of role, each student must access their knowledge related to the particular psychiatric diagnosis or problem and evidence-based communication and treatment recommendations. Students apply active listening techniques and the SBAR tool in "real-time" scenarios. The student must think critically and rapidly engage in solutions throughout each scene. Student observers have multiple opportunities for self-reflection, critical thinking, and the provision of active, professional, knowledgeable feedback for their colleagues through the various roles. These elements encourage an atmosphere of genuine curiosity, inquiry, discovery, illumination and teamwork which allows for the sharing of judgments and critical analysis within a milieu that fosters trust and openness as a foundation for learning and growth. This atmosphere is one where the adult learner (the student as well as faculty) is able to incorporate deep learning of clinical expertise to meet goals specified by the faculty and goals that emerge from the dynamic simulation experience itself, including being a member of a health care team trained to work autonomously, to provide ethical and critical feedback, and to access team expertise as needed.

The PMHN simulation experience also engages the students in legal and ethical debate. The unfolding cases charge the students to grapple with and understand challenges related to the patients' as well as the providers' experience and concerns. Opportunities for learning include questioning the nature of "good" patient care and "good" nursing assessment. Ethical practice dilemmas, such as issues of maleficence, beneficence, autonomy, social justice 
and the denial of rights, arise when grappling with complexities of psychiatric diagnosing and treatment, such as medication administration, side effects, and ensuring patient safety. Students explore the limitations and strengths of current practice knowledge and services. Students are challenged to "meet and treat the patient as a person" and "preserve the patient's personhood and dignity in the face of the ravages of ...illness...." (Benner et al., 2010, p. 192-3).

The PNCI Simulation Evaluation Tool (2012) provides an opportunity for students to reflect on the value and limitations of the experience, and also as an opportunity for faculty to understand the students' experience of the simulation day and to evaluate the strengths and deficits of the curriculum and the faculty's performance. Students have been consistently enthusiastic regarding the positive effects of the simulations. Students believe that the simulations clarify and reinforce what they are learning in the theory section of the course. Students strongly agree that the scenarios improve professional role performance in real life situations through critical thinking and decision making practice in a small group environment. Students state that observation of peers and active involvement as patient or provider built team work, trust, confidence, and assessment and therapeutic communication skills, allowing for "mistakes without fear of patient harm or distress". They report better understanding of how a client may feel, think or experience the clinical milieu and practice of providers.

These PMHN simulations provide a valuable alternative to on-site clinical placement as this pedagogical modality provides an intensive learning experience for the student as well as the faculty. Students are able to examine their own selves (emotional, intellectual, behavioral, professional); the role of the nurse, including personal challenges to that individual student related to diagnosis, therapeutic communication and the nursing process; and the experience of the client as an individual who suffers from mental illness, utilizes a variety of treatments, and engages with mental health personnel and institutions. Students can engage with their fears of making a mistake and their understanding of the level of responsibility of the nurse in practice, while developing their technical skills. Students act as students but also as teachers. Faculty educate and evaluate, and also learn. The simulation experience engages not just knowledge and teamwork, but also creativity and play.

Challenges of these mental health simulations exist, but can be addressed. The day-long simulation requires a time commitment for faculty as well as students. Extensive faculty input is required to develop the day-long as well as to actualize it. Because of the intensity of the learning experience, including the active engagement of all aspects of the individual, students and faculty can be exhausted (and invigorated) by day's end.

One challenge of having the PMHN simulation earlier in the course is that the students do not have the knowledge gained through didactic lecture as well as observation/experience at the clinical site, and thus would not be able to so readily apply this knowledge to the role play.
However, the early simulation day, by focusing more on professional role, therapeutic communication, and challenging issues, and then on evidence-based diagnoses and treatment, provides an opportunity for self-assessment and faculty assessment of student knowledge, skill levels, attitudes and needs.

Some challenge that simulation replaces valuable time at clinical sites working with real clients and mental health personnel. Others suggest that students would benefit from even more on-site clinical days being replaced by simulation. Certainly this would provide some relief from the over-crowded scheduling of nursing students at clinical sites, and allow for a more controlled "experience" with simulated scenarios, peer-to-peer learning, and more focused in-the-moment feedback and assessment of students.

Multiple skills are required of the faculty who engages students in a simulation. Faculty must have the ability to develop a productive and engaging simulation format that will meet learning objectives. In addition, faculty must be capable of spontaneously demonstrating the complex qualities that allow for establishing a non-judgmental milieu where actions, judgments and concerns can be examined, made visible, valued and, where indicated, transformed. In the rapid-fire world of simulation, unpredictable scenarios and emotions can emerge. The faculty must have the emotional, intellectual and professional maturity to recognize and address these situations and needs in a manner that builds students' development into expert clinicians. The student can emerge from the simulation experience as a more actualized individual and professional.

\section{Recommendations}

The use of simulation in teaching PMHN and therapeutic communication is an emerging pedagogy with multidisciplinary potential. Further research is needed to evaluate this particular model for efficacy as well as for utility across health professions. This could include collecting data, assessing students pre- and post-simulation and of students in classes that did not have this opportunity. Use of standardized tools for evaluation of student satisfaction and self-confidence are important. We must find standardized tools that measure objective learning and real efficacy in terms of outcomes related to student knowledge, skill and attitude development, outcomes related to patient safety and effective illness prevention and treatment, and efficacy in teamwork. Building and utilizing more scenarios that engage faculty and students across disciplines is recommended. Providing a simulation related to communication and assessment skills early in the semester prior to the start of clinical is recommended. Threading an evidence-based model for therapeutic communication, such as Motivational Interviewing, throughout the curriculum would enhance student skill development, and link PMHN theory and clinical, as well as PMHN to future theory and clinical courses. Students could be utilized in the sample 
demonstration video. Faculty may develop more creative uses for the stored videos of student simulations such as developing portfolios; if these are not of use, storage may not be necessary. These opportunities would contribute meaningful data that could be utilized to build on this model as well as improve care. Faculty must remain open to feedback and ongoing evaluation of student educational needs. The PNCI Simulation Evaluation Tool (SET, 2012) could be revised to reflect objectives of simulation related to mental health issues. A number of students recommended that the tool utilize the term "client" rather than "patient". Replication of the simulation day and gathering more feedback and assessment data from students and faculty may deepen and solidify learning and understanding of the value of this work, and provide evidence for improving the pedagogy.

\section{Conclusions and Implications}

The ground breaking work, Educating Nurses: A Call for Radical Transformation, states: "To begin to develop the integrative thinking that professionals draw on in complex practice, nursing students need to acquire knowledge in a way that relates directly to the skilled know-how and ethical comportment they are developing in clinical situations, and to acquire knowledge in ways that allow them to imagine situations and rehearse for them" (Benner et al., 2010, p. 128). The PMHN therapeutic communication simulation experience provides a safe, challenging experiential learning environment that demonstrates an engaged application of didactic learning of classification systems, signs, symptoms, and interventions to actual assessment and intervention for the mental health nursing student. Each student's experience, knowledge, skills, attitudes and needs are challenged, evaluated and enhanced. Students act as the "patient", deepening their understanding of the diagnosis and the experience of that whole person; as the "professional", applying situational knowledge and professional judgment; and as the "mentor" or observer, facilitating teamwork. Students engage in uncertainty about situations and self with the guidance of experts. There is time for challenging patterns of thinking, feeling, behaving and knowing; for deliberation; for deep thinking, and thus, for personal and professional growth of the professional nurse of the future.

\section{REFERENCES}

[1] American Association of Colleges of Nursing (2008). The essentials of baccalaureate education for professional nursing practice. Accessed September 2, 2012. http://www.aacn.nche.edu/Education/pdf/BaccEssentials08.p df.

[2] Bambini, D., Washburn, J. and Perkins, R. (2009). Outcomes of clinical simulation for novice nursing students:
Communication, confidence, clinical judgment. Nursing Education Perspectives, 30(2), pp. 79-82 doi: 10.1043/1536-5026-030.002.0079.

[3] Barnett, D., Everly, G. S., Parker, C. L. \& Links, J. M. (2005). Applying educational gaming to public health workforce emergency preparedness. American Journal of Preventative Medicine, 28(4), 490-495.

[4] Belford, M. (2004). Shoulder dystocia and flying airplanes. Obstet Gynecol, 104, 658-660.

[5] Benner, P., Sutphen, M., Leonard, V. \& Day, L. (2009). Nursing education: A call for radical transformation. San Francisco: Jossey-Bass.

[6] Bligh, J. \& Bleakley, A., (2006). Distributing menus to hungry learners: Can learning by simulation become simulation of learning? Medical Teacher, 28 (7), 606-613.

[7] Bosse, H. M., Nickel, M., Huwendiek, S. , Junger, J., Schultz, J. H., \& Nikendei, C. (2010). Peer role-play and standardized patients in communication training: A comparative study on the student perspective on acceptability, realism, and perceived effect. BMC Medical Education, 10 (27), 1-9.

[8] Brown, J. F. (2008). Application of simulation technology in psychiatric mental health nursing education. Journal of Psychiatric Mental Health Nursing, 15 (8), 638-44.

[9] Bush, M., Jankouskas, T., Sinz, E., Rudy, S., Henry, J., \& Murray, W. B. (2007). A method of designing symmetrical simulation scenarios for evaluation of behavioral skills. Simulation in Healthcare, 2, 102-109.

[10] Comer, S. K. (2005). Patient care simulations: role playing to enhance clinical understanding. Nursing Education Perspectives, 26, 357-361.

[11] Davis, S., Josephsen, J., and Macy, R. (2012). Implementation of mental health simulations: Challenges and lessons learned. Clinical simulation in nursing, e1-e6.

[12] Guise, V., Chamber, M., Valinski, M. (2012). What can virtual patient simulation offer mental health nursing education? Journal Psychiatric Mental Health Nursing, 19 (5), 410-8.

[13] Healthy People. Mental health and mental disorders. Healthypeople.gov/2020/topicsobjectives2020/overview.asp $\mathrm{X}$

[14] Hermanns, M., Lilly, M., Crawley, B. (2011). Using clinical simulation to enhance psychiatric nursing training of baccalaureate students. Clinical Simulation in Nursing, 7 (2), e41-e46.

[15] Issenberg, S.B. \& Scalese, R.J., (2008). Simulation in health care education. Perspectives in Biology and Medicine, 51 (1), $31-46$.

[16] Jeffries, P.R., Editor (2007). Simulation in nursing education, from conceptualization to evaluation. NY: National League of Nursing.

[17] Jeffries, P.R., Woolf, S., \& Linde, B. (2003). Technology-based vs. traditional instruction. A comparison of two methods for teaching the skill of performing a 12-lead ECG. Nursing Education Perspectives, 24 (2), 70-74.

[18] Kameg, K., Howard, V.M., Clochesy, J., Mitchell, A. M. \& 
Suresky, J. M. (2010). The impact of high fidelity human simulation on self-efficacy of communication skills. Issues in Mental Health Nursing, 31, 315-323.

[19] Kardong-Edgren, S,E., Starkweather, A.R., \& Ward, L.D., (2008). The integration of simulation into a clinical foundations of nursing course: Student and faculty perspectives. International Journal of Education Scholarship, $5(1), 1-16$.

[20] Kessler, R. C., Chiu, W., Demler, O. (2005). Prevalence, severity and comorbidity of twelve-month DSM-IV disorders in the National Comorbidity Survey Replication. Archives of General Psychiatry, 62(6), 617-27.

[21] Kidd, L. I., Morgan, K. I. \& Savery, J. R. (2012). Development of a mental health nursing simulation: Challenges and solutions. Journal of Interactive Online Learning. 11 (2), 80-89.

[22] Kluge, M.A. \& Glick, L. (2006). Teaching therapeutic communication via camera cues and clues: The video inter-active (VIA) method. Journal of Nursing Education, 45 (11), 463-468.

[23] Linder, L.A. \& Pulsipher, N. (2008). Implementation of simulated learning experiences for Baccalaureate pediatric nursing students. Clinical Simulation in Nursing, 4 (3), $41-47$.

[24] McCausland, L.L., Curran, C.C., \& Cataldi, P. (2004). Use of a human simulator for undergraduate nursing education. International Journal of Nursing Education Scholarship, 1 (1), 23 .

[25] McGaghie, W. C., Issenberg, S. B., Petrusa, E. R., \& Scalese, R. J. (2006). Effect of practice on standardized learning outcomes in simulation-based medical education. Medical Education, 40, 792-797.

[26] Miller, G., (1990). The assessment of clinical skills/ competence/performance. Academic Medicine, 65 (Supp. 9), 563-567.

[27] National League of Nursing (2005). Core competencies of nurse educators. http://www.nln.org/facultyprograms/pdf/corecompetencies.p df

[28] Nehring, W. M. \& Lashley, F. R. (2004) Current use and opinions regarding human patient simulators in nursing education: an international survey. Nursing Education Perspectives, 25, 244-248.

[29] O'Connell, M. E., Boat, T., Warner, K. E. (ed), (2009). Preventing mental, emotional, and behavioral disorders among young people: Progress and possibilities. National Research Council and Institute of Medicine, Committee on the Prevention of Mental Disorders and Substance Abuse Among Children, Youth and Young Adults. Washington:
National

[30] Academies Press, p. 18 http://www.iom.edu/Reports/2009/Preventing-Mental-Emoti onal-and-Behavioral-Disorders-Among-Youth-People-Progr ess-and-Possibilities.aspx . ISBN-13: 978-0-309-12674-8.

[31] QSEN (2005). Pre-licensure knowledge, skills and attitudes. Quality and Safety Education for Nurses [QSEN]. http://qsen.org/competencies/pre-licensure-ksas/ Rauen, C., (2004). Simulation as a teaching strategy for nursing education and orientation in cardiac surgery. Critical Care Nurse, 24 (3), 46-51.

[32] Rauen, C. (2004). Simulation as a teaching strategy for nursing education and orientation in cardiac surgery. Critical Care Nursing, 24 (3), 46-51.

[33] Ravert, P. (2002). An integrative review of computer-based simulation in the education process. CIN: Computers, Informatics, Nursing, 20 (5), 203-208.

[34] Rhodes, M.L. \& Curran, C. (2005). Use of the human patient simulator to teach clinical judgment skills in a Baccalaureate nursing program. CIN: Computers, Informatics, Nursing, September/October, 256-262.

[35] Robertson, B. (2006). An obstetric simulation experience in an undergraduate nursing curriculum. Nurse Educator, 31 (2), 74-78.

[36] Robinson-Smith, G., Bradley, P. K., \& Meakim, C. (2009). Evaluating the use of standardized patients in undergraduate psychiatric nursing experiences. Clinical Simulation in Nursing, 5 (6), e203-e211.

[37] Rudolph, J. W., Simon, R., Dufresne, R. L., \& Raemer, D.B. (2006). There's no such thing as "nonjudgmental" debriefing: A theory and method for debriefing with good judgment. Simulation in Healthcare, 1 (1), 49-55.

[38] Simon R., Raemer, D. B., Rudolph, J. W. (2009). Debriefing assessment for simulation in healthcare. Center for Medical Simulation, Cambridge: MA.

http://www.harvardmedsim.org/debriefing-assesment-simula tion- healthcare.php. Accessed July 22, 2012.

[39] Simulation Effectiveness Tool (2012). Program for Nursing Curriculum (PNCI). CAE Healthcare, Sarasota, FL. https://caehealthcare.com/.../Simulation_Effectivness_Tool 0812

[40] Sleeper, J.A. \& Thompson, C. (2008). The use of hi fidelity simulation to enhance nursing students' therapeutic communication skills. International Journal of Nursing Scholarship, 5 (1), 1-12.

[41] Starkweather, A. R., \& Kardong-Edgren, S. (2008). Diffusion of innovation: Embedding simulation into nursing curricula. International Journal of Nursing Education Scholarship, 5(1), 1-11. 